\title{
Development of a clinical transition pathway for adolescents in the Netherlands
}

Walter M, Hazes JMW, Dolhain RJEM et al (2017) Development of a clinical transition pathway for adolescents in the Netherlands. Nursing Children and Young People. 29, 9, 37-43. Date of submission: 30 March 2017; date of acceptance: 17 July 2017. doi: I0.7748/ncyp.2017.e932

\section{Margot Walter}

Nurse practitioner, Department of Rheumatology, Erasmus Medical Center, Rotterdam, the Netherlands

\section{Johanna MW Hazes \\ Professor, Department of Rheumatology, Erasmus Medical Center, Rotterdam, the Netherlands}

\section{Radboud JEM Dolhain Rheumatologist, Department of Rheumatology, Erasmus Medical Center, Rotterdam, the Netherlands}

\section{Philomine van Pelt}

Rheumatologist, Department of Rheumatology, Erasmus Medical Center, Rotterdam, the Netherlands

\section{Annette van Dijk \\ Specialist rheumatology nurse (paediatric team), Department of Rheumatology, Erasmus Medical Center, Rotterdam, the Netherlands}

\section{Sylvia Kamphuis,}

Paediatric rheumatologist, Department of Rheumatology, Erasmus Medical Center, Sophia Children's Hospital, Rotterdam, the Netherlands

\section{Correspondence} m.walter@erasmusmc.nl

Conflict of interest None declared

\begin{abstract}
Aims To explore how young people with juvenile-onset rheumatic and musculoskeletal diseases (jRMDs) and their parent(s) experience care during preparation for the upcoming transfer to adult services, and to develop a clinical transition pathway.
\end{abstract}

Method A survey was conducted with 32 young people aged between 14 and 20 years with jRMDs, and their parents ( $n=33$ ), treated at the department of paediatric rheumatology in a tertiary care children's hospital in the Netherlands.

Results More than $30 \%$ of young people would have liked to discuss topics such as educational and vocational choices in a clinic, but did not get the opportunity. Preparation for transition was poor as was training in self-management skills. One third of parents had feelings of anxiety about the upcoming transfer. Results from the survey and evidence-based principles of transitional care were used to develop the clinical transition pathway. The pathway focuses on starting transition early, developing self-management skills, joint consultations and supporting parents in giving young people control of their clinical care.

Conclusion Care does not currently meet the needs of young people in the process of transition to adult rheumatology services. The clinical transition pathway developed as a result of the study is a tool that may improve this process.

\section{Keywords}

child health, clinical transition pathway, juvenile-onset rheumatic and musculoskeletal diseases, transition of care, young people

TRANSITION IS the planned transfer of care for young people with a chronic disease from children's to adult services (Blum et al 1993, McDonagh 2005, Foster et al 2017). It involves a period of preparation, the transition process, during which young people are trained in the skills necessary for a successful transfer (McDonagh 2005, Foster et al 2017). If transition is not well managed, however, it will have an adverse effect on the quality, continuity and efficiency of care (Campbell et al 2016).

Several transition programmes and guidelines have been developed over the past decade to support the process (McDonagh et al 2007, Hilderson et al 2016, National Institute for Health and Care Excellence (NICE) 2016, Singh et al 2016, Foster et al 2017). These transition programmes result in better quality of life, increased knowledge and satisfaction for adolescents, and better prevocational readiness (Robertson et al 2006, McDonagh et al 2007, Shaw et al 2007).
However, implementation of transitional care is not widespread in routine clinical practice for young people with chronic diseases, including juvenile-onset rheumatic and musculoskeletal diseases (jRMDs) (Clemente et al 2016, Hilderson et al 2016, Foster et al 2017). Despite the availability of transition programmes for these young people, half of them do not make a successful transfer and they are often inadequately supported during the transition process (Hazel et al 2010, Chanchlani et al 2015, Singh et al 2016, Foster et al 2017).

A clinical transition pathway is a tool to make implementation of transition programmes into routine clinical practice easier. Reviews on transition and transition guidelines have reported several important points that need to be incorporated into care. Overarching principles are planned, developmentally appropriate and holistic care.

A transition coordinator is essential, as is good collaboration between children's 


\section{Peer review}

This article has been subject to open peer review and has been checked for plagiarism using automated software

\section{Acknowledgement}

We would like to thank Janet McDonagh for letting us use the 'Dream Team UK' individual transition plan as the basis for the Dutch clinical transition pathway and adult's services (Singh et al 2016,

Foster et al 2017).

During the development process for a specific clinical pathway, it is important to investigate the status of care and identify potential problems and bottlenecks experienced by patients (Vanhaecht and Sermeus 2002). Surveys that explore patients' preferences and opinions can be used for this purpose (Polit and Beck 2016).

\section{Aims}

The aims of this study were to:

»Explore how young people with $\mathrm{jRMDs}$ and their parent(s) experience care during preparation for the upcoming transfer to adult services.

»Develop a clinical transition pathway.

\section{Method}

All young people with jRMDs aged 1420 years, and their parents, treated at the department of paediatric rheumatology in a tertiary care children's hospital in the Netherlands were invited to participate. Separate surveys were developed for patients and their parents based on evidence from the literature and discussions with a paediatric rheumatologist (SK), a rheumatologist from the adult care team (RD) and two specialist rheumatology nurses from the paediatric (AD) and adult care team (MW).

The survey included four open and 35 multiple-choice questions (MCQs) for patients and five open and 13 MCQs for parents. The surveys included questions about demographics, topics that should have been discussed in clinic but were not, experiences of preparation for transfer and achievement of self-management skills. At the time the

\begin{tabular}{|c|c|}
\hline Respondents & $n=32$ \\
\hline Mean age: years (range) & $17(14-20)$ \\
\hline Female: $n(\%)$ & $22(69)$ \\
\hline $\begin{array}{l}\text { Diagnosis: } n \text { (\%) } \\
\text { " Juvenile idiopathic arthritis } \\
\text { " Childhood-onset systemic lupus } \\
\text { erythematosus } \\
\text { " Granulomatosis with polyangiitis } \\
\text { " Eosinophilic fasciitis } \\
\text { » Henoch-Schönlein purpura }\end{array}$ & $\begin{array}{c}23(72) \\
6(19) \\
1(3) \\
1(3) \\
1(3)\end{array}$ \\
\hline Mean time since diagnosis: years (range) & $6.2(0.5-16)$ \\
\hline
\end{tabular}

study was conducted, the department of paediatric rheumatology had no specific policy or protocol about the process of transition.

The development of the clinical transition pathway was based on the principles of Vanhaecht and Sermeus (2002) (Vanhaecht et al 2006). This method consists of 11 steps in four phases: the plan-do-check-act cycle (Hoekstra et al 2003). Results from the patient and parent surveys were incorporated into the clinical transition pathway.

\section{Data analysis}

Descriptive statistics were used to analyse the results from the MCQs in the surveys. Answers to open questions were labelled and coded; these codes were grouped into concepts. Two researchers (SK, MW) independently analysed the open questions. Differences were discussed until consensus was reached.

\section{Ethical considerations}

All patients and parents gave informed consent and the ethical review board of the hospital approved the study.

\section{Results}

A total of 48 surveys were sent to patients and a total of 48 were sent to parents. The overall response rate was $67 \%(n=32)$ patients and $69 \%(n=33)$ parents. Patients' mean age was 17 years (range 14-20) with a mean disease duration of 6.2 years (range $0.5-16$ ). Most (72\%) had juvenile idiopathic arthritis (Table 1).

\section{Clinic discussions}

When asking the young people if they missed topics that were never discussed during consultations, $35 \%(n=10)$ reported they missed discussion of at least one of the following topics:

»Educational and vocational choices.

»Alcohol/drugs.

»Sexuality.

"Leisure-time activities.

"Of parents, $21 \%(n=7)$ said they missed topics and would have liked to discuss at least one of the same topics during consultations. Two parents also wanted to receive information about fertility and medication.

Experiences of preparation for transfer Six questions investigated preparation for transition. The answers are summarised below. Almost half of patients never thought about the transfer to adult care and $50 \%$ were not 
informed about the upcoming transfer. The other half heard about transition during the study through a verbal remark that they would soon be transferred to the adult team. No further information was given according to patients. Only three received more information about the differences between children's and adult clinics. Of patients $16 \%(n=5)$ experienced anxiety about the transition. Half said they would like to meet the adult care team before the transfer.

About one third of patients did not expect a difference between the approaches of the children's and adults' teams. Those who did expect a difference mentioned a change in approach with less personal attention and older patients in the waiting room, while others did not know what the difference would be.

Of parents, $70 \%(n=23)$ had thought about the transfer to the adult team, but did not find it necessary to discuss this subject at an earlier stage. However, when specifically asked about the upcoming transfer, almost one third $(n=10)$ of parents had feelings of anxiety and insecurity, and $10 \%(n=4)$ had mixed feelings. Most parents expected to experience a difference; they mentioned a less personal approach and being treated more maturely.

Patients' self-management skills

Eleven questions referred to self-management skills (Table 2). The first question on selfmanagement was preparation for the consultation. A total of $59 \%$ of the patients prepared questions before the consultation and only half asked questions during the consultation.

In total, $29(91 \%)$ patients were familiar with their diagnosis and $28(88 \%)$ indicated they had enough knowledge about their disease to take care of themselves independently. This was in line with the results from the parents' survey; most parents thought their child had enough knowledge about the disease and medication to take care of themselves. Most $(n=30,94 \%)$ patients knew what medication they used, but only $18(56 \%)$ knew its side effects. Only $12(38 \%)$ patients thought about taking the medication themselves without the help of their parents. Additionally, only eight $(25 \%)$ patients ordered prescriptions from the pharmacy and five $(16 \%)$ made the clinic appointment themselves.

The patients' degree of independence is an important self-management skill. Almost all $88 \%(n=28)$ patients attended the outpatient clinic with their parents. Reasons for attending with their parents included fear of forgetting what physicians had told them, finding it difficult to ask questions independently, fear of forgetting questions that needed to be asked, requiring transport to the hospital and parents who insisted on attending. Of parents, $38 \%(n=13)$ thought their child could not visit the clinic independently. Half of the parents recognised the importance of their child visiting the hospital independently, but this was not yet current practice. The parents who recognised the importance of independent visits preferred to make this transition in a gradual way.

Developing the clinical transition pathway All results from the patient and parent surveys were used to develop a clinical transition pathway, based on the principles of Vanhaecht and Sermeus (2002) (Vanhaecht et al 2006).

In brief, the principles for developing the clinical pathway were: starting to investigate the problem, forming a project team, performing a literature search and

\section{Online archive} For related information, visit nursingchildren andyoungpeople. co.uk and search using the keywords

\section{TABLE 2. Young people's survey questions on self-management tasks}

\begin{tabular}{|c|c|c|c|}
\hline & & $\begin{array}{c}\text { Yes } \\
(n=32)\end{array}$ & $\%$ \\
\hline \multicolumn{2}{|c|}{ Prepared questions before the consultation } & 19 & 59 \\
\hline \multicolumn{2}{|c|}{ Asked questions during the consultation } & 16 & 50 \\
\hline \multirow{3}{*}{$\begin{array}{l}\text { Made appointment } \\
\text { independently }\end{array}$} & » Patients alone & 5 & 16 \\
\hline & »Parents and patients & 9 & 28 \\
\hline & »Parents alone & 18 & 56 \\
\hline \multicolumn{2}{|l|}{ Familiar with diagnosis } & 29 & 91 \\
\hline \multicolumn{2}{|c|}{ Had enough knowledge about the disease to take care of themselves independently } & 28 & 88 \\
\hline \multicolumn{2}{|c|}{ Knew what medication to use } & 30 & 94 \\
\hline \multicolumn{2}{|c|}{ Knew what the medication was for } & 27 & 84 \\
\hline \multicolumn{2}{|c|}{ Knew the medication side effects } & 18 & 56 \\
\hline \multirow{3}{*}{$\begin{array}{l}\text { Thought about taking the } \\
\text { medication }\end{array}$} & » Patients alone & 12 & 38 \\
\hline & »Parents and patients & 15 & 47 \\
\hline & »Parents & 4 & 13 \\
\hline \multirow{3}{*}{$\begin{array}{l}\text { Ordered the medication } \\
\text { at the pharmacy }\end{array}$} & » Patients alone & 8 & 25 \\
\hline & »Parents and patients & 3 & 9 \\
\hline & »Parents & 20 & 63 \\
\hline \multicolumn{2}{|c|}{ Young person injected the medication themselves } & $9(n=15)$ & 60 \\
\hline
\end{tabular}


Figure I. Clinical transition pathway

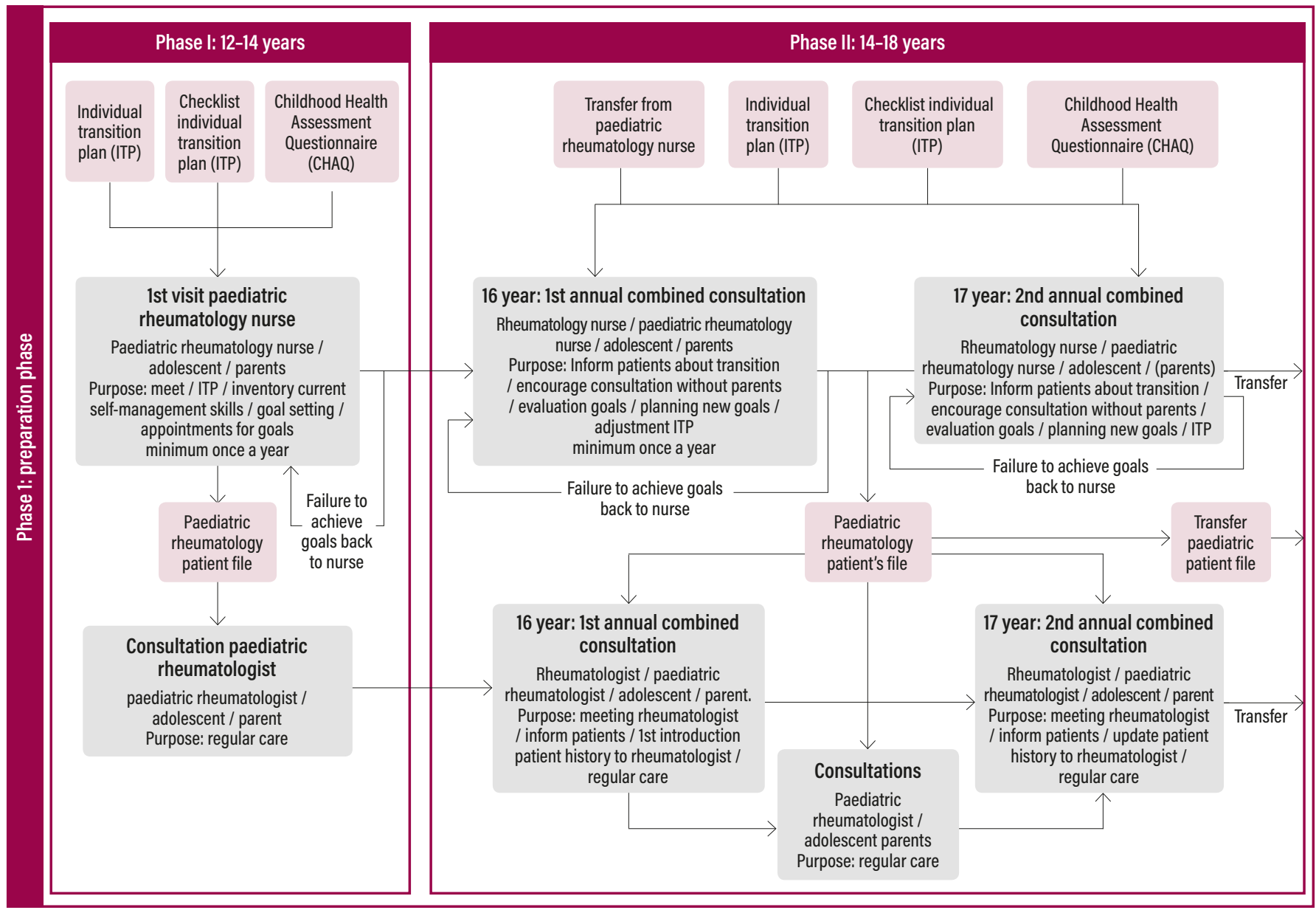

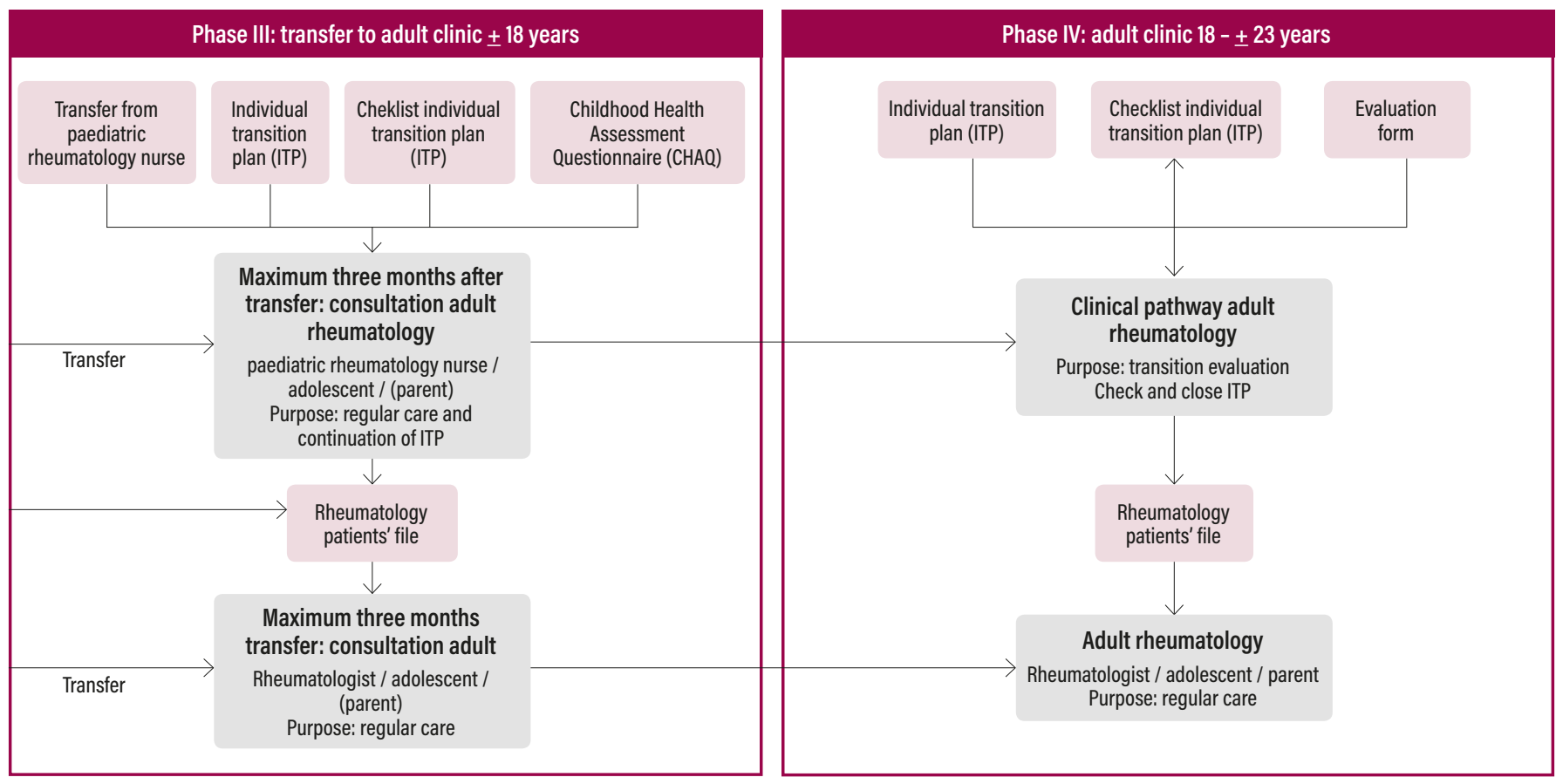


benchmarking, implementing the clinical pathway, testing the clinical pathway and making adjustments. The last phase is the evaluation.

Evidence-based principles of transitional care were incorporated into the design of the clinical transition pathway (van Staa et al 2011, Cruikshank et al 2016, Foster et al 2017). These principles are also described in the NICE (2016) guideline on transition (Singh et al 2016). The principles are:

"The availability of a transition coordinator and age-appropriate care.

"An early start: 12-14 years.

» The use of an individual transition plan (ITP).

" Joint consultations with professionals from children's and adults' services.

»Support for parents in allowing their children to take control of managing their disease (Barlow et al 2002, Shaw et al 2004a, 2007, McDonagh 2005, 2007, Robertson et al 2006, van Staa et al 2011).

»Holistic person-centred care, which addresses not only medical care but also psychosocial and vocational needs (McDonagh 2008, Bridgett et al 2015). The ITP developed by McDonagh et al (2006, 2015) was used, with permission, to develop the clinical transition pathway. The ITP was divided into three age categories (12-14, 14-16 and 16-18+ years), each with ageappropriate questions covering ten domains. The ITP includes checklists at the end of each age category reflecting which domain goals are achieved and which domains need specific attention in the following period. An ITP to support and guide parents in the transition process was also developed (McDonagh et al 2006, 2015). The Childhood Health Assessment Questionnaire (CHAQ) was incorporated in the transition pathway. The CHAQ measures functional status and is validated for different juvenile rheumatic conditions (Tennant et al 2001, Meiorin et al 2008).

The availability of a transition coordinator is vital for the success of the clinical transition pathway. The specialist rheumatology nurse from the paediatric rheumatology team is the designated transition coordinator and coordinates the clinical transition pathway from the start to the transfer to adult care. This nurse provides substantive patient support and ensures the smooth running of the process. After transfer to adult care, a member of the adult care team takes over as transition coordinator. Both transition coordinators are in close contact with each other.
Figure 1 depicts the clinical transition pathway. All patients aged 12 years and older who visit the outpatient clinic of the department of paediatric rheumatology receive care as outlined in Figure 1. When patients reach the age of 16 and 17 , joint consultations are planned with the paediatric rheumatologist, the rheumatologist, the specialist paediatric rheumatology nurse and the nurse from the adult team.

The purpose of the joint consultation is to allow patients and their parents to become acquainted with the adult team and ask questions. The adult team also gets the chance to become acquainted with the young person and be informed about the treatment plan. Knowledge of the treatment plan in childhood and understanding why certain choices were made is important for the rheumatologist to ensure alignment of treatment after transfer. Actual transfer to the adult clinic occurs around the age of $16-18$ years, where timing of the transfer depends on the patient's achieved skills and personal wishes.

\section{Discussion}

This study explored how patients with jRMDs and their parent(s) experience care during the preparation for the upcoming transfer to adult services, and used the results to develop a clinical transition pathway.

Patients and their parents thought current care at the paediatric rheumatology department did not prepare them well enough for the upcoming transfer to adult care. This included lack of discussion of relevant topics in clinic, neglect in self-management skills training and insufficient knowledge about the differences in care between the children's and adult departments. These themes influenced the development of the clinical transition pathway.

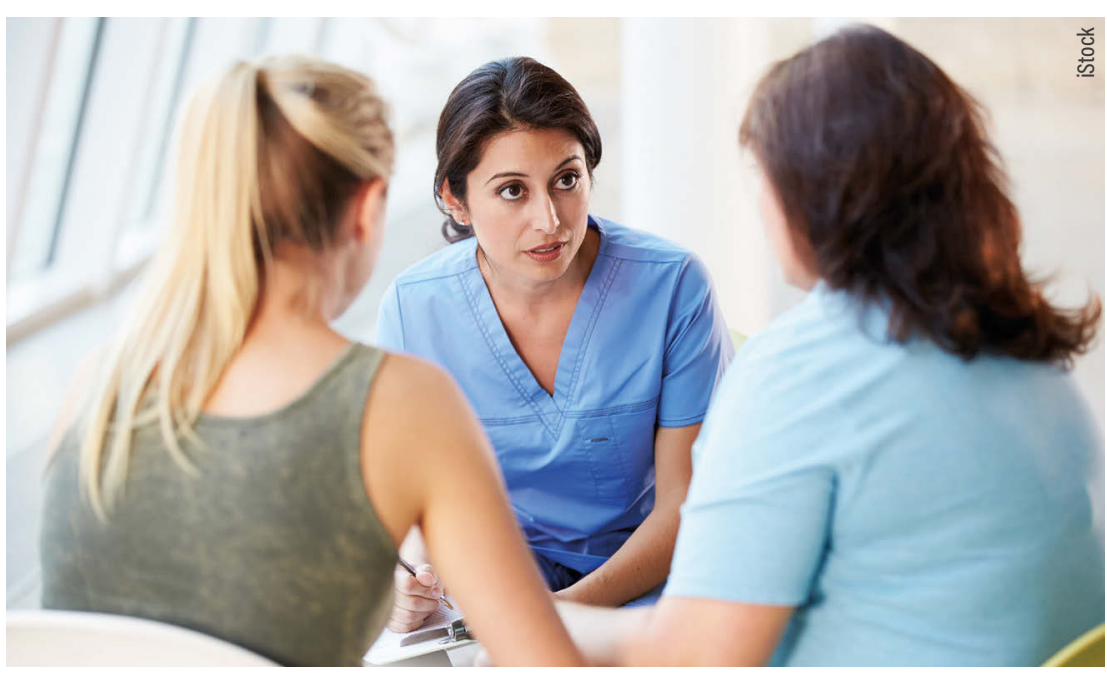

Write for us

For information about writing for $\mathrm{RCNi}$ journals, contact writeforus@rcni.com

For author guidelines, go to reni.com/ writeforus 
The lack of discussion of topics such as education, vocational needs, sexuality and use of alcohol has been reported in other studies (van Staa et al 2007, Hilderson et al 2012). Discussing these topics and providing information is important and may support the development of self-management skills in decision-making (Rosen 2004, Shaw et al 2004a, Shaw et al 2004b). Adolescents often do not address these topics themselves during consultations (McDonagh et al 2006), possibly because they are accompanied by their parents. In the study, almost none of the patients visited healthcare professionals independently.

Confidence to see health professionals without parents is an important skill for successful transition and supports the development of autonomy (Robertson et al 2006, McDonagh and Hackett 2008, Wells et al 2012). Adolescents who visit the doctor without their parents tend to participate more actively in the consultations (McDonagh and Kelly 2003). Hence, preparing patients from a young age to attend consultations independently is important.

Other self-management skills were also underdeveloped, for example, making appointments, seeking advice for intercurrent complaints and renewing prescriptions.

By implementing an ITP early in the transition phase that addresses all these aspects, goals can be formulated, and plans made to stimulate and amplify self- management skills. This will teach young people skills necessary for a successful transition and help them to cope with their disease later in life (Robertson et al 2006, Wells et al 2012). A transition plan is also recommended by NICE (2016) (Singh et al 2016). Many studies support the transition process starting early, ideally at the beginning of adolescence (11-12 years) and at the latest by the age of 14 (White 2002, McDonagh 2008, Hilderson et al 2013, Nagra et al 2015, Foster et al 2017).

When asked about the differences between children's and adult care, patients and their parents had little understanding. For example, on the one hand you have adult care that is disease oriented and, on the other hand, you have children's care which is socially oriented. Another difference is the emphasis on treatment and compliance with little or no attention to development, school/study or social function in adult care (Fleming et al 2002).

In addition, they were not always aware of the upcoming transfer to adult care. It is important for patients and parents to understand the differences between the two departments and be prepared for the culture gap (Robertson et al 2006). This may diminish the feelings of anxiety and uncertainty that parents and patients reported when asked about the upcoming transfer to adult care. Anxiety is an obstruction in the transition process (Fleming et al 2002). These

\section{References}

Barlow J, Wright C, Sheasby J et al (2002) Selfmanagement approaches for people with chronic conditions: a review. Patient Education and Counseling. 48, 2, 177-187.

Betz CL, Redcay G (2005) Dimensions of the transition service coordinator role. Journal for Specialists in Pediatric Nursing. 10, 2, 49-59.

Betz CL, Cowell JM, Craft-Rosenberg MJ et al (2007) Health care quality and outcome guidelines for nursing of children and families: implications for pediatric nurse practitioner practice, research, and policy. Journal of Pediatric Health Care 21, 1, 64-66.

Blum RW, Garell D, Hodgman CH et al (1993) Transition from child-centered to adult health-care systems for adolescents with chronic conditions. A position paper of the Society for Adolescent Medicine. The Journal of Adolescent Health. 14, 7 570-576.

Bridgett M, Abrahamson G, Ho J (2015) Transition, it's more than just an event: supporting young people with type 1 diabetes. Journal of Pediatric Nursing. 30,5, el1-14.
Campbell F, Biggs K, Aldiss SK et al (2016) Transition of care for adolescents from paediatric services to adult health services. Cochrane Database of Systematic Reviews. Issue 4. CD009794.

Chanchlani N, McGee M, McDonagh JE (2015) Informational continuity is integral for successful transition of adolescents to adult care. The Journal of Rheumatology, 42, 5, 901-902

Clemente D, Leon L, Foster H et al (2016) Systematic review and critical appraisal of transitional care programmes in rheumatology. Seminars in Arthritis and Rheumatism. 46, 3, 372-379.

Crowley R, Wolfe l, Lock Ket al (2011) Improving the transition between paediatric and adult healthcare: a systematic review. Archives of Disease in Childhood. 96, 6, 548-553.

Cruikshank M, Foster HE, Stewart J et al (2016) Transitional care in clinical networks for young people with juvenile idiopathic arthritis: current situation and challenges. Clinical Rheumatology. $35,4,893-899$

Eleftheriou D, Isenberg DA, Wedderburn LR et al (2014) The coming of age of adolescent rheumatology. Nature Reviews. Rheumatology. 10, 3, 187-193.
Fleming E, Carter B, Gillibrand W (2002) The transition of adolescents with diabetes from the children's health care service into the adult health care service: a review of the literature. Journal of Clinical Nursing. 11, 5, 560-567

Foster HE, Minden K, Clemente D et al (2017) EULAR/ PReS standards and recommendations for the transitional care of young people with juvenileonset rheumatic diseases. Annals of the Rheumatic Diseases. 76, 4, 639-646

Hazel E, Zhang X, Duffy CM et al (2010) High rates of unsuccessful transfer to adult care among young adults with juvenile idiopathic arthritis. Pediatric Rheumatology Online Journal. 8,2.

Hilderson D, Moons P, Westhovens R et al (2012) Attitudes of rheumatology practitioners toward transition and transfer from pediatric to adult healthcare. Rheumatology International. 32, 12 3887-3896.

Hilderson D, Eyckmans L, Van der Elst Ket al (2013) Transfer from paediatric rheumatology to the adult rheumatology setting: experiences and expectations of young adults with juvenile idiopathic arthritis. Clinical Rheumatology. 32, 5, 575-583.
Hilderson D, Moons P, Van der Elst Ket al (2016) The clinical impact of a brief transition programm for young people with juvenile idiopathic arthritis: results of the DON'T RETARD project. Rheumatology. $55,1,133-142$

Hoekstra TS, Vanhaecht K, Sermeus W (2003) Het klinisch pad CABG. TVZ - Tijdschrift voor verpleegkundige. 3,50-55

Lugasi T, Achille M, Stevenson M (2011) Patients perspective on factors that facilitate transition from child-centered to adult-centered health care: a theory integrated metasummary of quantitative and qualitative studies. The Journal of Adolescent Health. 48, 5, 429-440.

McDonagh JE (2005) Growing up and moving on: transition from pediatric to adult care. Pediatric Transplantation. 9, 3,364-372.

McDonagh JE (2007) Transition of care from paediatric to adult rheumatology. Archives of Disease in Childhood. 92, 9, 802-807.

McDonagh JE (2008) Young people first, juvenil idiopathic arthritis second: transitional care in rheumatology. Arthritis and Rheumatism. $59,8,1162-1170$. 
feelings may be decreased further if patients and their parents can meet their new healthcare provider before the actual transfer (Rosen 2004, McDonagh et al 2006, Lugasi et al 2011).

A minimum of two annual combined consultations at ages 16 and 17 have been incorporated into the clinical transition pathway (Figure 1). Here, young people and their parents are offered a joint consultation with the children's and adult care team together in the same room.

Parents need to be guided during the transition process, because it is important for them to feel confident about their changing role. Parents can be overprotective, which may have a negative effect on their child's developing independence (Eleftheriou et al 2014). Therefore, an ITP to support parents in giving young people control of their clinical care was incorporated in the clinical transition pathway.

Studies have shown the importance of transition coordinators in guiding young people and ensuring all their transition needs are met (Betz et al 2007, Crowley et al 2011, NICE 2016, Singh et al 2016). This role is best fulfilled by nurse specialists as they are trained to address young people's physical, psychosocial and educational needs (McDonagh et al 2006, Nagra et al 2015) and they can improve transition outcomes (Betz and Redcay 2005).

The clinical transition pathway has been incorporated into the routine care of the rheumatology department and is now under evaluation. Its effect will be reported in a future article.

\section{Limitations}

Study limitations include the small sample size, of patients receiving treatment in a tertiary care hospital in one year. Although the sample was small, the response rate was relatively high (32 of 48) for a survey (Stringer et al 2015). It is possible that those who did not complete surveys would have responded differently; however, the results were comparable with other studies.

\section{Conclusion}

This study explored the experience of care in the transition phase. We found that the clinical care does not meet the needs of young people with jRMDs during the transition process. These unmet needs existed because of a lack of discussion of relevant topics, neglected self-management skills training and insufficient knowledge about the differences in care between the children's and adult departments. Parents were also not guided in the transition process of their child which led to feelings of anxiety for the upcoming transfer to adult care. The clinical transformation pathway, developed in the light of the survey results, is a tool that can be used to improve this transition process by providing holistic care appropriate to young people's developmental stage and support their parents in this process.

\section{Implications \\ for practice}

"There is a need for transitional care. Ad hoc transition will lead to problems.

"Young people with jRMDs and their parents must be prepared for transition.

» The transition pathway outlined in the article can help to provide efficient, continuous, developmental and appropriate care.
McDonagh JE, Hackett J (2008) Interrelationship of self-management and transitional care needs of adolescents with arthritis: comment on the article by Stinson et al. Arthritis and Rheumatism. 59, 8 1199-1200; author reply 1200-1201.

McDonagh JE, Hackett J, McGee M et al (2015) The evidence base for transition is bigger than you might think. Archives of Disease in Childhood. Education and Practice Edition. 100, 6, 321-322.

McDonagh JE, Kelly DA (2003) Transitioning care of the pediatric recipient to adult caregivers. Pediatric Clinics of North America. 50, 6, 1561-1583.

McDonagh JE, Shaw KL, Southwood TR (2006) Growing up and moving on in rheumatology: development and preliminary evaluation of a transitional care programme for a multicentre cohort of adolescents with juvenile idiopathic arthritis. Journal of Child Health Care. 10,1,22-42.

McDonagh JE, Southwood TR, Shaw KL (2007) The impact of a coordinated transitional care programme on adolescents with juvenile idiopathic arthritis. Rheumatology. 46, 1, 161-168.

Meiorin S, Pistorio A, Ravelli A et al (2008) Validation of the Childhood Health Assessment Questionnaire in active juvenile systemic lupus erythematosus. Arthritis and Rheumatism. 59, 8, 1112-1119.

Nagra A, McGinnity PM, Davis N et al (2015) Implementing transition: Ready Steady Go. Archives of Disease in Childhood. Education and Practice Edition. 100, 6, 313-320.

National Institute for Health and Care Excellence (2016) Transition from children's to adults' services for young people using health or social care services. NICE Guideline 43. nice.org.uk/guidance/ ng43 (Last accessed: 31 August 2017.)

Polit DF, Beck CT (2016) Nursing Research: Generating and Assessing Evidence for Nursing Practice. Tenth edition. Lippincott Williams \& Wilkins, Philadelphia PA.

Robertson LP, McDonagh JE, Southwood TR et a (2006) Growing up and moving on. A multicentre UK audit of the transfer of adolescents with juvenile idiopathic arthritis from paediatric to adult centred care. Annals of the Rheumatic Diseases. 65, 1,74-80.

Rosen DS (2004) Transition of young people with respiratory diseases to adult health care. Paediatric Respiratory Reviews. 5, 2, 124-131.
Shaw KL, Southwood TR, McDonagh JE (2004a) Developing a programme of transitional care for adolescents with juvenile idiopathic arthritis: results of a postal survey. Rheumatology. 43,2 211-219.

Shaw KL, Southwood TR, McDonagh JE (2004b) Use perspectives of transitional care for adolescents with juvenile idiopathic arthritis. Rheumatology. $43,6,770-778$.

Shaw KL, Southwood TR, McDonagh JE (2007) Young people's satisfaction of transitional care in adolescent rheumatology in the UK. Child: Care, Health and Development. 33, 4,368-379

Singh SP, Anderson B, Liabo Ket al (2016) Supporting young people in their transition to adults' services: summary of NICE guidance. BMJ. 353:i2225.

Stringer E, Scott R, Mosher D (2015) Evaluation of a rheumatology transition clinic. Pediatric Rheumatology Online Journal. doi: 10.1186/s12969-015-0016-x

Tennant A, Kearns S, Turner F et al (2001) Measuring the function of children with juvenile arthritis. Rheumatology. 40, 11, 1274-1278. van Staa AL, Jedeloo S, Kuijper M et al (2007) Op Edigen Benen. Jongeren met chronische aandoeningen: wat willen en kunnen zij in de zorg? Rotterdam University, the Netherlands.

van Staa AL, Jedeloo S, van Meeteren J et al (2011) Crossing the transition chasm: experiences and recommendations for improving transitional care of young adults, parents and providers. Child: Care, Health and Development. 37, 6, 821-832

Vanhaecht K, Sermeus W (2002) Draaiboek voor de ontwikkeling, implementatie en evaluatie van een klinisch pad. Acta Hospitalia. 3, 13-27.

Vanhaecht K, De Witte K, Depreitere R et al (2006) Clinical pathway audit tools: a systematic review. Journal of Nursing Management. 14,7,529-537.

Wells CK, McMorris BJ, Horvath KJ et al (2012) Youth report of healthcare transition counseling and autonomy support from their rheumatologist. Pediatric Rheumatology Online Journal. 10, 1,36.

White PH (2002) Transition: a future promise for children and adolescents with special health care needs and disabilities. Rheumatic Diseases Clinics of North America. 28, 3, 687-703, viii 